\title{
Assessment of cognitive function in patients with myasthenia gravis
}

\author{
Sherifa A. Hamed ${ }^{1}$, Ahmad H. Youssef ${ }^{1}$, Mohamad A. Abd ElHameed ${ }^{1}$, Mohamed F. Mohamed ${ }^{1}$, \\ Amal M. Elattar ${ }^{2}$ \\ ${ }^{1}$ Department of Neurology and Psychiatry, Assiut University Hospital, Assiut 71516, Assiut, Egypt. \\ ${ }^{2}$ Department of ENT, Audiology Unit, Assiut University Hospital, Assiut 71516, Assiut, Egypt.
}

\section{A B S T R A C T}

Aim: During the past decade, there has been an increasing interest in the evaluation of cognitive function in myasthenia gravis (MG), neuromuscular transmission disorder caused by acetylcholine receptor auto-antibodies. However, the results of previous studies on cognition and MG are inconsistent and controversial. This study aimed to evaluate cognition in patients with mild/moderate grades of MG. Methods: This study included 20 patients with MG with a mean age of $28.45 \pm 8.89$ years and duration of illness of $3.52 \pm 1.15$ years. Cognition was tested using a sensitive battery of psychometric testing (Mini-mental State Examination [MMSE], Stanford-Binet Intelligence Scale $4^{\text {th }}$ edition [SBIS] and Wechsler Memory Scale-Revised [WMS-R]) and by recording P300 component of event-related potentials (ERPs), a neurophysiological analog for cognitive function. Results: Compared with healthy subjects $(n=20)$, patients had lower total scores of cognitive testing (MMSE, SBIS and WMS-R) $(P=0.001)$, higher Beck Depression Inventory $2^{\text {nd }}$ edition scores $(P=0.0001)$ and prolonged latencies $(P=0.01)$ and reduced amplitudes $(P=0.001)$ of P300 component of ERPs. Correlations were identified between total scores of cognitive testing and age $(r=-0.470, P=0.010)$, duration of illness $(r=-0.788, P=0.001)$ and depression scores $(r=-0.323, P=0.045)$. Using linear regression analysis and after controlling for age and depression scores, a significant correlation was identified between total scores of cognitive testing and duration of illness ( $\beta=-0.305, P=0.045)$. Conclusion: Patients with mild/moderate MG may have cognitive dysfunction. This is important to determine prognosis and managing patients.

Key words: Cognition, myasthenia gravis, nicotinic acetylcholine receptors

\section{INTRODUCTION}

Myasthenia gravis (MG) is an autoimmune disease caused mainly by auto-antibodies against skeletal muscle nicotinic acetylcholine receptors (nAChRs) at the postsynaptic membrane resulting in depletion of ACh at the neuromuscular junction. ${ }^{[1]} \mathrm{MG}$ is uncommon with a prevalence of $(25-125) / 10^{6}$. The disease tends to affect women more often than men (3:2) in their second and third decades. ${ }^{[2]}$ The cardinal symptoms of MG are fatigue and weakness of skeletal muscles with repeated or sustained exertion in the course of the day but improved by rest. Ocular muscles are initially involved in about $2 / 3$ of patients then spread

\begin{tabular}{|c|c|}
\hline \multicolumn{2}{|c|}{ Access this article online } \\
\hline Quick Response Code: & \\
\hline & $\begin{array}{l}\text { Website: } \\
\text { www.nnjournal.net }\end{array}$ \\
\hline & $\begin{array}{l}\text { DOI: } \\
10.4103 / 2347-8659.143671\end{array}$ \\
\hline
\end{tabular}

to the bulbar and limb muscles. Approximately, $85 \%$ of patients develop generalized weakness. Many patients progress from mild to severe disease, and if weakness of respiratory muscles becomes severe enough to require mechanical ventilation, the patient is said to be in crisis. ${ }^{[3]}$ Spontaneous remissions are very rare and last for varying periods that mostly occur during the first 3 years of the disease ${ }^{[4]}$ In adults, the thymus gland is abnormal in up to $90 \%$ of people with MG with approximately $70 \%$ of them have thymic hyperplasia while 10-20\% have benign thymic tumors or thymoma. ${ }^{[5]}$ The currently used treatment modalities for MG include acetyl choline esterase inhibitors (AChE-Is) (as pyridostigmine), ${ }^{[6]}$ immunopharmacologic drugs (as prednisone, ${ }^{[7]}$ azathioprine ${ }^{[8]}$ cyclosporine, ${ }^{[9]}$ mycophenolate mofetil,, ${ }^{[10]}$ cyclophosphamide, ${ }^{[11]}$ tacrolimus $^{[12]}$ and rituximab $\left.{ }^{[13]}\right)$ plasmapharesis, ${ }^{[14]}$ intravenous immunoglobulins (IVIGs) ${ }^{[15]}$ and thymectomy. ${ }^{[16]}$

Subjective impairments of memory and other cognitive functions are very frequent in patients with MG, however, previous studies, which investigated cognitive 
function in such patients showed contradictory results. Some reported memory difficulties and other cognitive dysfunction $^{[17-21]}$ and electroencephalographic (EEG) abnormalities. ${ }^{[22-24]}$ In contrast, others reported lack of neuropsychological impairments, normal intelligence, attention, memory and motor performance with MG. ${ }^{[25-27]}$

The exact mechanisms of the co-morbid cognitive dysfunction in patients with MG are unknown. The most likely suggested mechanism is central cholinergic deficiency due to the involvement of central neuronal nAChRs and other cholinergic nervous systems and pathways by the immune-mediated processes of MG. ${ }^{[20,28-30]}$ However, controversial views suggest that the co-morbid nervous system manifestations with MG may result from nonspecific mechanisms as complications of $\mathrm{MG}$, which include respiratory impairment, sleep apnea and hypoxia, ${ }^{[31-33]}$ mental fatigue, ${ }^{[26,27,34]}$ adverse effects from medications used for treatment of MG and mood disorder. ${ }^{[35,36]}$

This study aimed to investigate cognitive function in adults with mild/moderate MG. Cognitive functions were assessed using a battery of sensitive psychometric testing in addition to recording event-related potentials (ERPs), a neurophysiological analog of cognitive function.

\section{METHODS}

\section{Subjects}

This study included 20 patients (males $=6$, females $=14$ ) diagnosed clinically and electrophysiologically as MG. Their age ranged from 16 to 50 years, and duration of illness ranged from 1 to 4 years. Clinical grading of the patients was done based on the medical, scientific advisory board of MG Foundation of America classification. ${ }^{[37]}$ Patients grading was based on their histories and diagnoses shown in their medical records. Patients reported histories of weakness of ocular muscles (ptosis) (class I), of mild and predominant weakness of the limb muscles (class II a) or oropharyngeal muscles (class II b), or with moderate and predominant weakness of the limb muscles (class III a). Before the presentation, all patients were treated with AChE-Is (pyridostigmine bromide or mestinon in a dose of $60 \mathrm{mg} / 4 \mathrm{~h}$ during the daytime and $60 \mathrm{mg}$ at night time), immunotherapy with prednisolone and/or azathioprine (imuran) or plasmapharesis. Thymectomies were performed to the seven patients with thymoma. Table 1 shows the demographic and clinical characteristics of the studied group. Patients were recruited from the Out-patient Clinic of the Department of Neurology, Assiut University Hospital, Assiut, Egypt during their follow-up visits in which

\begin{tabular}{|c|c|c|c|}
\hline $\begin{array}{l}\text { Demographic and clinical } \\
\text { characteristics }\end{array}$ & $\begin{array}{c}\text { Patients } \\
(n=20) \\
(\%)\end{array}$ & $\begin{array}{c}\text { Control } \\
\text { subjects } \\
(n=20)(\%)\end{array}$ & $P$ \\
\hline Male/female & $4 / 16$ & $10 / 10$ & - \\
\hline Age (years) & $\begin{array}{c}16-50 \\
28.45 \pm 8.89\end{array}$ & $\begin{array}{c}20-50 \\
30.22 \pm 5.76\end{array}$ & 0.380 \\
\hline Duration of illness (years) & $\begin{array}{c}1-4 \\
3.52 \pm 1.15\end{array}$ & - & - \\
\hline \multicolumn{4}{|l|}{ Clinical grade } \\
\hline 1 & 0 & - & - \\
\hline IIa/IIb & $2 / 10$ & - & - \\
\hline IIIa/IIIb & $8 / 0$ & - & - \\
\hline IVa/IVb & 0 & - & - \\
\hline V & 0 & - & - \\
\hline \multicolumn{4}{|l|}{ Thymic pathology } \\
\hline Normal & $5(25)$ & - & - \\
\hline Hyperplasia & $8(40)$ & - & - \\
\hline Thymoma & 7 (35) & - & - \\
\hline \multicolumn{4}{|l|}{$\begin{array}{l}\text { Previous treatment (single or } \\
\text { combination of the followings) }\end{array}$} \\
\hline $\begin{array}{l}\text { Acetyl choline esterase } \\
\text { inhibitors }\end{array}$ & $20(100)$ & - & - \\
\hline Prednisolone & $20(100)$ & - & - \\
\hline Azathioprine & $8(40)$ & - & - \\
\hline Plasmapharesis & $9(45)$ & - & - \\
\hline Thymectomy & $7(25)$ & - & - \\
\hline
\end{tabular}

Data are expressed as range, mean \pm SD, $n(\%)$. SD: standard deviation

they were free of clinical manifestations (i.e. after resolution of active stage of the disease for at least 3 months) and were on maintenance treatment with low doses of AChE-Is and/or steroids. Twenty healthy subjects matched for age, sex and socioeconomic status were included in this study for statistical comparisons. Control subjects were recruited from the general population. This study was accepted by the regional Ethical Committee. Detailed information on the study was given to all patients, and control subjects, and all gave their written consent to attend the study.

We excluded subjects (patients and controls) with: (1) respiratory involvement or in crisis (i.e. severe stages of the disease); (2) history of other primary neurological (e.g. transient ischemic attacks, cerebrovascular stroke or epilepsy), psychiatric (e.g. major depression) or medical (e.g. diabetes mellitus) diseases which are known to affect cognition; (3) previous serious head injury; (4) any sensory or motor disorder that would preclude psychological testing (as blindness or deafness); and (5) regular treatment with medications (other than those used for treatment of MG) which may alter cognitive testing (e.g. as benzodiazepines, beta-adrenoceptor antagonists, major tranquillizers and antidepressants).

\section{Electroencephalographic recording}

Electroencephalographic was done using the eight channels Nihon Kohden machine (4217), employing scalp electrodes placed according to the international 10-20 system with bipolar and referential montages. 
Hyperventilation and photic stimulation were used as provocation tests.

\section{Cognitive assessment}

Cognitive functions were assessed independently for each participant by two experienced psychologists and under supervision of a psychiatrist, using a set of standardized Arabic translated neuropsychological tests that are sensitive for mild cognitive impairment and covering different cognitive domains. They included: Mini-Mental State Examination (MMSE), ${ }^{[38,39]}$ Stanford-Binet Intelligence Scale $4^{\text {th }}$ edition (SBIS) ${ }^{[40,41]}$ and Wechsler Memory Scale-Revised (WMS-R). ${ }^{[42]}$ From SBIS, we selected vocabulary and comprehension for assessment of verbal reasoning, pattern analysis for assessment of visual reasoning, quantitation for quantitative reasoning, and bead memory and memory for sentences for short-term memory. From WMS-R, we tested digit forward digit backward, mental control, associate learning, logical memory, and visual reproduction.

\section{Event related potentials testing}

Before examining ERPs, all participants underwent basic audiological testing (Amplaid Model 720, Milan, Italy). Testing for ERPs was done on a separate day after completion of neuropsychological testing (Neuropack S1 EMG/EP measuring system, MEB-9400 (Nihon Kohden, Japan). ERPs are series of scalp waves that are extracted from the EEG by time domain analysis and averaging of EEG activity following multiple stimulus repetitions. They were elicited with an auditory discrimination task paradigm by presenting a series of biaural $1000 \mathrm{~Hz}$ (standard) versus $2000 \mathrm{~Hz}$ (target) tones at $70 \mathrm{~dB}$ with a $10 \mathrm{~ms}$ rise/fall and $40 \mathrm{~ms}$ plateau time. P300, the late component of ERPs was obtained. Latencies and amplitudes (peak to peak) of P300 component of ERPs were measured. The P300 wave is a positive deflection in the human ERPs. It is most commonly elicited in an "oddball” paradigm when a subject detects an occasional "target" stimulus in a regular train of standard stimuli. The P300 wave only occurs if the subject is actively engaged in the task of detecting the targets. Its amplitude varies with the improbability of the targets. Its latency varies with the difficulty of discriminating the target stimulus from the standard stimuli. Typical peak latency is elicited when a young adult subject makes a simple discrimination in $300 \mathrm{~ms}$. In patients with decreased cognitive ability, the P300 is smaller and later than in age-matched normal subjects. The P300 have multiple intra-cerebral generators, with the hippocampus and various association areas of the neocortex contribute to the development of this potential. The P300 component of ERPs represents the transfer of information to consciousness, a process that involves many different regions of the brain. ${ }^{[43]}$
Psychological evaluation

Standardized psychiatric interview was done by applying the Diagnostic and Statistical Manual of Mental Health Disorders, $4^{\text {th }}$ edition (DSM-IV) criteria for the diagnosis of depression. ${ }^{[4]}$ A differentiation between clinical depression and depressive symptoms was made throughout clinical interview of the patient. The Arabic version ${ }^{[45]}$ of the Beck Depression Inventory, $2^{\text {nd }}$ edition (BDI-II) ${ }^{[46]}$ was used to assess the severity of depressive symptoms. BDI-II items are in alignment with DSM-IV criteria. BDI-II consists of 21 items each corresponds to a symptom of depression summed to give a single score for the BDI-II. According to that scale, the patient may have, not having or has minimal depressive symptoms if scoring 0-13, mild symptoms if scoring 14-19, moderate symptoms if scoring 20-28 and severe symptoms if scoring 29-63.

\section{Statistical analysis}

Calculations were done with the statistical package SPSS, version 12.0 (SPSS Inc. Chicago, IL, USA). Data were presented as mean \pm standard deviation. Student's $t$-test was used for comparison of means. Correlations between score of cognitive testing and demographic and clinical characteristics and depression scores were assessed using Pearson's test. Linear regressions analyses were done using the total score of cognition testing as the dependent variable and age, duration of illness and depression scores as independent variables. For all tests, $P<0.05$ was considered as significant.

\section{RESULTS}

This study included 20 patients with MG. They had a mean age of $28.45 \pm 8.89$ years and duration of illness of $3.52 \pm 1.15$ years. Patients reported normal EEG records. All patients had depressive symptoms of mild ( $n=15$, $75 \%)$ and moderate $(n=5,25 \%)$ severities. Each patient had a different combination of abnormalities in various cognitive testing subsets particularly WMS-R ( $n=16,80 \%$ ). Patients had significantly lower scores of MMSE, different subsets of SBIS, WMS-R and total scores of cognitive testing (MMSE, SBIS and WMS-R) $(P=0.0001)$ and higher scores of BDI-II ( $P=0.0001)$ [Table 2]. The majority of patients had abnormalities in latency and/or amplitude of P300 component of ERPs $(n=14,70 \%)$. Patients had significantly prolonged latencies $(P=0.01)$ and reduced amplitudes $(P=0.001)$ of $P 300$ component of ERPs [Table 3]. Significant correlations were identified between total scores of cognitive testing and P300 latency, P300 amplitude, age, duration of illness and depression scores [Table 4] Using linear regression analysis and after controlling for age and depression scores, significant correlation was identified between 
Table 2: Comparison between patients and controls in scores of cognitive functions and depression

\begin{tabular}{|c|c|c|c|}
\hline Variable & $\begin{array}{l}\text { Patients } \\
(n=20)\end{array}$ & $\begin{array}{l}\text { Controls } \\
(n=20)\end{array}$ & $P$ \\
\hline MMSE & $23.25 \pm 2.35$ & $27.56 \pm 1.45$ & 0.036 \\
\hline \multicolumn{4}{|l|}{ SBST } \\
\hline Vocabulary & $36.33 \pm 5.45$ & $50.45 \pm 3.88$ & 0.042 \\
\hline Comprehension & $35.46 \pm 9.07$ & $49.76 \pm 7.56$ & 0.007 \\
\hline $\begin{array}{l}\text { Total verbal reasoning } \\
\text { score }\end{array}$ & $75.32 \pm 8.85$ & $96.82 \pm 16.25$ & 0.0001 \\
\hline Visual reasoning & $36.63 \pm 4.64$ & $48.68 \pm 5.04$ & 0.0001 \\
\hline $\begin{array}{l}\text { Total visual reasoning } \\
\text { score }\end{array}$ & $68.43 \pm 8.09$ & $88.33 \pm 14.70$ & 0.0001 \\
\hline Quantitative test & $36.57 \pm 6.54$ & $45.30 \pm 5.43$ & 0.0001 \\
\hline $\begin{array}{l}\text { Total quantitative } \\
\text { reasoning score }\end{array}$ & $75.53 \pm 8.67$ & $96.65 \pm 9.57$ & 0.0001 \\
\hline Bead memory & $45.30 \pm 7.28$ & $60.50 \pm 10.08$ & 0.0001 \\
\hline Memory for sentences & $44.72 \pm 6.34$ & $65.56 \pm 8.57$ & 0.0001 \\
\hline $\begin{array}{l}\text { Total score for } \\
\text { short-term memory }\end{array}$ & $85.65 \pm 9.66$ & $150.25 \pm 25.26$ & 0.0001 \\
\hline Total score of SBST & $289.56 \pm 55.48$ & $360.34 \pm 50.04$ & 0.0001 \\
\hline $\mathrm{IQ}$ & $78.53 \pm 6.46$ & $95.35 \pm 8.73$ & 0.0001 \\
\hline \multicolumn{4}{|l|}{ WMS-R } \\
\hline Digit forward & $4.56 \pm 1.01$ & $6.64 \pm 0.88$ & 0.035 \\
\hline Digit backward & $2.23 \pm 0.25$ & $5.58 \pm 0.45$ & 0.010 \\
\hline Mental control & $3.57 \pm 1.45$ & $5.89 \pm 1.06$ & 0.042 \\
\hline Logical memory & $10.65 \pm 1.30$ & $14.83 \pm 2.45$ & 0.007 \\
\hline Associate learning & $8.52 \pm 2.04$ & $12.06 \pm 2.24$ & 0.005 \\
\hline $\begin{array}{l}\text { Total scores of cognitive } \\
\text { testing (MMSE, SBST } \\
\text { and WMS-R) }\end{array}$ & $76.54 \pm 8.35$ & $96.54 \pm 6.28$ & 0.0001 \\
\hline Depression scores & $20.64 \pm 6.24$ & $8.65 \pm 3.55$ & 0.0001 \\
\hline
\end{tabular}

Data are expressed as mean \pm SD. SBST: stanford Binet subtests testing, MMSE: mini-mental state examination, WMS-R: wechsler memory scale-revised, SD: standard deviation, IQ: intelligence quotient

Table 3: Comparison between patients and controls in event-related potentials

\begin{tabular}{lccc} 
Variable & Patients $(\boldsymbol{n}=\mathbf{2 0})$ & Controls $(\boldsymbol{n}=\mathbf{2 0})$ & $\boldsymbol{P}$ \\
\hline $\mathrm{P}_{\text {300 }}$ latency $(\mathrm{ms})$ & & & \\
$\quad$ Right sided & $250.00-450.00$ & $285.00-353.00$ & - \\
& $350.80 \pm 35.88$ & $320.88 \pm 25.75$ & 0.010 \\
Left sided & $270.00-450.00$ & $250.00-350.00$ & - \\
& $355.60 \pm 33.08$ & $325.45 \pm 20.45$ & 0.010 \\
& & & \\
$\mathrm{P}_{300}$ amplitude $(\mathrm{mv})$ & & $6.88-20.54$ & - \\
Right sided & $2.20-20.25$ & $12.45 \pm 2.84$ & 0.001 \\
& $7.55 \pm 2.45$ & $6.80-22.25$ & - \\
Left sided & $2.55-18.09$ & $12.63 \pm 2.56$ & 0.001 \\
& $6.67 \pm 3.23$ & & \\
\hline
\end{tabular}

Data are expressed as range, mean \pm SD. SD: standard deviation

Table 4: Pearson's correlation ( $r$ and $P$ value) between

total scores of cognitive testing and clinical variables, lab variables, depression scores and ERPs variables

Variables

Total scores of cognitive

testing (MMSE, SBST and WMS-R)

$r$

$\mathrm{P}_{300}$ latency

$-0.650$

0.557

$-0.470$

Age

$-0.788$

$-0.323$

Depression scores

ERPs: event-related potentials, MMSE: mini-mental state examination,

SBST: stanford Binet subtests testing, WMS-R: wechsler memory scale-revised

total scores of cognitive testing (MMSE, SBIS and WMS-R) and duration of illness $(\beta=-0.305, P=0.045)$.

\section{DISCUSSION}

The results of this study indicate that patients with mild/moderate MG may experience significant manifestations of cognitive impairment in the absence of disease activity and despite the short duration of illness. Patients with MG may experience poor performance in different cognitive tasks indicating central or brain involvement. These included deficits in verbal relations, comprehension, visual reasoning, pattern analysis, quantitation, bead memory, short-term memory and memory for sentences, digit forward, digit backward, mental control, logical memory, and associate learning. In the agreement with our findings, patients with MG commonly reported subjective cognitive complaints. In patients with MG, several previous studies reported memory difficulties ${ }^{[17,18]}$ and impaired performance on varieties of cognitive tests as MMSE and memory tests, ${ }^{[19]}$ the Boston Naming Test, the Logical Memory and Design Reproduction portions of the WMS, Rey Auditory Verbal Learning Test, ${ }^{[17]}$ and measures of response fluency, information processing and verbal and visual learning. ${ }^{[20,21,47]}$ In additions, the detected abnormalities in P300 component of ERPs also suggest the central or brain involvement in MG. In fact, abnormal evoked potential responses were noted in patients with MG. ${ }^{[48-50]}$ In contrast, several studies reported normal IQ, memory, attention and motor performance and normal ERPs in MG. ${ }^{[25-27]}$ We believe that such discrepancies could be explained by differences in methodologies, small sample size, different lists of inclusion and exclusion criteria and lack of control for potential confounding variables.

Several mechanisms have been hypothesized as etiologies of cognitive impairment in patients with MG. The central cholinergic deficiency due to the involvement of the central nAChRs and central cholinergic pathways by the disease process of MG have been suggested as the high likely mechanisms. ${ }^{[20,28-30]}$ This hypothesis is based on the fact that there are structural identities between different muscle and neuronal nAChRs subunits with the possibility of cross-reactivity between different nAChRs antibodies. ${ }^{[51-53]}$ The hippocampus, a cerebral structure highly involved in learning and memory, has abundant cholinergic innervation and enriched in nAChRs that modulate synaptic plasticity via mechanisms involved in long-term potentiation. ${ }^{[54]}$ Few suggested that cognitive dysfunction co-morbidity may be due to the immune responses driven by muscle and neuronal nAChRs antibodies expressed by cancer (e.g. thymoma) (i.e. paraneoplastic syndrome). ${ }^{[55,56]}$ Others suggested that it might be a nonspecific autoimmune response in presence or absence of tumor. ${ }^{[57]}$ This it further supported by an association of MG with other nonnervous system medical 
immune-mediated disorders as diabetes mellitus, ${ }^{[58]}$ thyroiditis ${ }^{[59]}$ and systemic lupus erythematosis. ${ }^{[60]}$

Despite the strength of our findings, this study had some limitations which include: (1) a relatively small sample size that is explained by the fact that we included only a homogenous group of adults with mild/moderate MG in their remission stages and on maintenance treatment; (2) due to the cross-sectional nature of the study, the temporal relation between the disease stage and occurrence of cognitive deficits is difficult to be determined. Future research should include longitudinal studies that prospectively assess the relation of the disease process to cognition over time; (3) CSF analysis for determination of immune markers of the disease is missing as our ethical committee did not allow CSF sampling for uncomplicated patients. It has been realized that CSF examination better detects immune involvement of CNS, and (4) our investigation did not include testing for mental fatigue or sleep pattern. These factors cannot be excluded as causes or potentials for cognitive dysfunction with MG.

In conclusion, adults with mild/moderate MG may experience prominent cognitive deficits in different domains regardless to the presence of depression. This is important to determine prognosis and managing patients.

\section{REFERENCES}

1. Lindstrom JM, Seybold ME, Lennon VA, Whittingham S, Duane DD. Antibody to acetylcholine receptor in myasthenia gravis. Prevalence, clinical correlates, and diagnostic value. Neurology 1976;26:1054-9.

2. Phillips $\mathrm{LH} 2^{\text {nd }}$. The epidemiology of myasthenia gravis. Neurol Clin 1994;12:263-71.

3. Drachman DB. Myasthenia gravis. NEngl JMed 1994;330:1797-810.

4. Engel AG. Disturbances in neuromuscular transmission. In: Engel AG, Franzini-Armstrong C, editors. Myology. $2^{\text {nd }}$ ed. New York: McGraw-Hill; 1994. p. 1769-97.

5. Onodera $\mathrm{H}$. The role of the thymus in the pathogenesis of myasthenia gravis. Tohoku J Exp Med 2005;207:87-98.

6. Scheife RT, Hills JR, Munsat TL. Myasthenia gravis: signs, symptoms, diagnosis, immunology, and current therapy. Pharmacotherapy 1981;1:39-54

7. Bedlack RS, Sanders DB. Steroid treatment for myasthenia gravis: steroids have an important role. Muscle Nerve 2002;25:117-21.

8. Palace J, Newsom-Davis J, Lecky B. A randomized double-blind trial of prednisolone alone or with azathioprine in myasthenia gravis. Myasthenia Gravis Study Group. Neurology 1998;50:1778-83.

9. Tindall RS, Phillips JT, Rollins JA, Wells L, Hall K. A clinical therapeutic trial of cyclosporine in myasthenia gravis. Ann NY Acad Sci 1993;681:539-51.

10. Chaudhry V, Cornblath DR, Griffin JW, O'Brien R, Drachman DB Mycophenolate mofetil: a safe and promising immunosuppressant in neuromuscular diseases. Neurology 2001;56:94-6.

11. Drachman DB, Jones RJ, Brodsky RA. Treatment of refractory myasthenia: "rebooting" with high-dose cyclophosphamide. Ann Neurol 2003;53:29-34.

12. Ponseti JM, Azem J, Fort JM, Codina A, Montoro JB, Armengol M.
Benefits of FK506 (tacrolimus) for residual, cyclosporin- and prednisone-resistant myasthenia gravis: one-year follow-up of an open-label study. Clin Neurol Neurosurg 2005;107:187-90.

13. Pescovitz MD. Rituximab, an anti-cd20 monoclonal antibody: history and mechanism of action. Am J Transplant 2006;6:859-66.

14. Chiu HC, Chen $\mathrm{WH}$, Yeh JH. The six year experience of plasmapheresis in patients with myasthenia gravis. Ther Apher 2000;4:291-5.

15. Wegner B, Ahmed I. Intravenous immunoglobulin monotherapy in long-term treatment of myasthenia gravis. Clin Neurol Neurosurg 2002;105:3-8.

16. Gronseth GS, Barohn RJ. Practice parameter: thymectomy for autoimmune myasthenia gravis (an evidence-based review): report of the quality standards subcommittee of the American academy of neurology. Neurology 2000;55:7-15

17. Tucker DM, Roeltgen DP, Wann PD, Wertheimer RI. Memory dysfunction in myasthenia gravis: evidence for central cholinergic effects. Neurology 1988;38:1173-7.

18. Riker WF. Memory impairment in myasthenia gravis. Neurology 1989;39:611-2.

19. Iwasaki Y, Kinoshita M, Ikeda K, Takamiya K, Shiojima T. Cognitive dysfunction in myasthenia gravis. Int J Neurosci 1990;54:29-33.

20. Glennerster A, Palace J, Warburton D, Oxbury S, Newsom-Davis J Memory in myasthenia gravis: neuropsychological tests of central cholinergic function before and after effective immunologic treatment. Neurology 1996;46:1138-42.

21. Paul RH, Cohen RA, Gilchrist JM, Aloia MS, Goldstein JM. Cognitive dysfunction in individuals with myasthenia gravis. $J$ Neurol Sci 2000;179:59-64.

22. Hokkanen E, Toivakka E. Electroencephalographic findings in myasthenia gravis 180 EEG recordings of 109 patients. Acta Neurol Scand 1969;45:556-67.

23. Tartara A, Mola M, Manni R, Moglia A, Lombardi M, Poloni M, Piccolo G. EEG findings in 118 cases of myasthenia gravis. Rev Electroencephalogr Neurophysiol Clin 1982;12:275-9.

24. Kazis A, Pappa P, Xafenias D. EEG finding in myasthenia gravis. Electromyogr Clin Neurophysiol 1984;24:577-82.

25. Feldmann R, Kiefer R, Wiegard U, Evers S, Weglage J. Intelligence, attention, and memory in patients with myasthenia gravis. Nervenarzt 2005;76:960, 962-6.

26. Marra C, Marsili F, Quaranta D, Evoli A. Determinants of cognitive impairment in elderly myasthenia gravis patients. Muscle Nerve 2009;40:952-9.

27. Sitek EJ, Bilinska MM, Wieczorek D, Nyka WM. Neuropsychological assessment in myasthenia gravis. Neurol Sci 2009;30:9-14.

28. Vernino S, Cheshire WP, Lennon VA. Myasthenia gravis with autoimmune autonomic neuropathy. Auton Neurosci 2001;88:187-92.

29. Gotkine M, Fellig Y, Abramsky O. Occurrence of CNS demyelinating disease in patients with myasthenia gravis. Neurology 2006;67:881-3.

30. Hamed SA. Comorbid nervous system manifestations and disorders with myasthenia gravis: evidences and possible mechanisms. J Neurol Neurosci 2012;3:2.

31. Stepansky R, Weber G, Zeitlhofer J. Sleep apnea in myasthenia gravis. Wien Med Wochenschr 1996;146:209-10.

32. Amino A, Shiozawa Z, Nagasaka T, Shindo K, Ohashi K, Tsunoda S, Shintani S. Sleep apnoea in well-controlled myasthenia gravis and the effect of thymectomy. $J$ Neurol 1998;245:77-80.

33. Nicolle MW, Rask S, Koopman WJ, George CF, Adams J, Wiebe S. Sleep apnea in patients with myasthenia gravis. Neurology 2006;67:140-2.

34. Lewis SW, Ron MA, Newsom-Davis J. Absence of central functional cholinergic deficits in myasthenia gravis. $J$ Neurol Neurosurg Psychiatry 1989;52:258-61.

35. Paul RH, Cohen RA, Zawacki T, Gilchrist JM, Aloia MS. What have we learned about cognition in myasthenia gravis?: a review of methods and results. Neurosci Biobehav Rev 2001;25:75-81.

36. Paul RH, Cohen RA, Gilchrist JM. Ratings of subjective mental fatigue relate to cognitive performance in patients with myasthenia 
gravis. J Clin Neurosci 2002;9:243-6.

37. Jaretzki A $3^{\text {rd }}$, Barohn RJ, Ernstoff RM, Kaminski HJ, Keesey JC, Penn AS, Sanders DB. Myasthenia gravis: recommendations for clinical research standards. Task Force of the Medical Scientific Advisory Board of the Myasthenia Gravis Foundation of America. Ann Thorac Surg 2000;70:327-34.

38. Folstein MF, Folstein SE, McHugh PR. "Mini-mental state". A practical method for grading the cognitive state of patients for the clinician. J Psychiatr Res 1975;12:189-98.

39. Al-Rajeh S, Ogunniyi A, Awada A, Daif A, Zaidan R. Preliminary assessment of an Arabic version of the Mini-Mental state examination. Ann Saudi Med 1999;19:150-2.

40. Delany EA, Hopkins TF. The Stanford. Binet Intelligence Scale: Examiner's Handbook. $4^{\text {th }}$ ed. Chicago: The Riverside Publishing Co.; 1986

41. Melika LK. The Stanford. Binet Intelligence Scale: Arabic Examiner's Handbook. $4^{\text {th }}$ ed. Cairo: Dar El Maref Publishing; 1998.

42. Wechsler D. Wechsler Memory Scales-Revised. New York: Psychological Cooperation; 1987.

43. Polich J. P300 clinical utility and control of variability. J Clin Neurophysiol 1998;15:14-33.

44. American Psychiatric Association. Diagnostic and Statistical Manual of Mental Disorders. $4^{\text {th }}$ ed. Washington, DC: American Psychiatric Association; 1994. p. 317-91

45. Gharyb AG. Beck Depression Inventory-II (BDI-II), Arabic Examiner's Handbook. Cairo: Dar El-Anglo Publishing; 2000.

46. Beck AT, Steer RA, Ball R, Ranieri W. Comparison of beck depression inventories-IA and-II in psychiatric outpatients. $J$ Pers Assess 1996;67:588-97.

47. Bartel PR, Lotz BP. Neuropsychological test performance and affect in myasthenia gravis. Acta Neurol Scand 1995;91:266-70.

48. Kirby AW, Wiley RW, Harding TH. Cholinergic effects on the visual evoked potential. In: Cracco RQ, Bodis-Wollner I, editors. Evoked Potentials. Alan R. Liss, New York; 1986. p. 296-305.

49. Fotiou F, Papakostopoulos D, Hamlatzis P. Changes in the pattern reversal visual evoked potentials in myasthenia gravis. Electromyogr Clin Neurophysiol 1994;34:171-5.

50. Jech R, Ruzicka E. Brain stem auditory evoked potentials reflect central nervous system involvement in myasthenia gravis. J Neurol 1996;243:547-50.
51. Tzartos SJ, Sophianos D, Efthimiadis A. Role of the main immunogenic region of acetylcholine receptor in myasthenia gravis. An Fab monoclonal antibody protects against antigenic modulation by human sera. J Immunol 1985;134:2343-9.

52. Lindstrom J, Anand R, Peng X, Gerzanich V, Wang F, Li Y. Neurona nicotinic receptor subtypes. In: Diversity of Interacting Receptors. Birkhäuser Basel; 1995. p. 100-16.

53. Brejc K, van Dijk WJ, Klaassen RV, Schuurmans M, van Der Oost J, Smit AB, Sixma TK. Crystal structure of an ACh-binding protein reveals the ligand-binding domain of nicotinic receptors. Nature 2001:411:269-76.

54. Ji D, Lape R, Dani JA. Timing and location of nicotinic activity enhances or depresses hippocampal synaptic plasticity. Neuron 2001;31:131-41.

55. Darnell RB. Paraneoplastic neurologic disorders: windows into neuronal function and tumor immunity. Arch Neurol 2004;61:30-2

56. Evoli A, Minicuci GM, Vitaliani R, Battaglia A, Della Marca G, Lauriola L, Fattorossi A. Paraneoplastic diseases associated with thymoma. J Neurol 2007;254:756-62.

57. Thorlacius S, Aarli JA, Riise T, Matre R, Johnsen HJ. Associated disorders in myasthenia gravis: autoimmune diseases and their relation to thymectomy. Acta Neurol Scand 1989;80:290-5.

58. Low PA, Suarez GA. Diabetic neuropathies. Baillieres Clin Neurol 1995;4:401-25

59. Manfredi R, Fasulo G, Fulgaro C, Sabbatani S. Associated thyreoiditis, myasthenia gravis, thymectomy, Chron's disease, and erythema nodosum: pathogenetic and clinical correlations, immune system involvement, and systemic infectious complications. Rheumatol Int 2008;28:1173-5.

60. Tola MR, Casetta I, Granieri E, Caniatti LM, Monetti VC, Pascarella R. Systemic lupus erythematosus related recurrent transverse myelitis in a patient with myasthenia gravis and multiple sclerosis. Eur Neurol 1996;36:327-8

Cite this article as: Hamed SA, Youssef AH, Abd ElHameed MA, Mohamed MF, Elattar AM. Assessment of cognitive function in patients with myasthenia gravis. Neuroimmunol Neuroinflammation 2014;1(3):141-6.

Source of Support: Nil. Conflict of Interest: No.

Received: 14-07-2014; Accepted: 25-08-2014 